\title{
KRAS and BRAF mutational status in colon cancer from Albanian patients
}

\author{
Daniela Martinetti ${ }^{1}$, Rosario Costanzo ${ }^{1}$, Shahin Kadare ${ }^{2}$, Mehdiu Alimehmeti ${ }^{3}$, Cristina Colarossi ${ }^{4}$, \\ Vincenzo Canzonieri ${ }^{5}$, Massimiliano Berretta ${ }^{6}$ and Lorenzo Memeo ${ }^{1,4^{*}}$
}

\begin{abstract}
Background: Numerous clinical studies have shown that anti-EGFR therapies are effective only in a subset of patients with colorectal cancer. Mutations in the KRAS and BRAF genes have been confirmed as negative predictors of the response to EGFR-targeted therapies.

In this study we evaluated KRAS and BRAF status in 159 colorectal cancer samples obtained from the University of Tirana.
\end{abstract}

Methods: We evaluated KRAS mutations in codons 12, 13, 61, 146 and in codon 600 of BRAF by direct sequencing. 90 patients were male (57\%) and 69 female (43\%); the patients' ages ranged from 17 to 85 (median 61.7). 24 patient were stage I, 36 stage II, 84 stage III and 15 stage IV.

Results: Out of the 159 cases, 28 (17,6\%) showed KRAS mutation (13 G12D, 4 G12C, 4 G12V, 3 G12A, 2 G13 D, 1 G12S and $1 \mathrm{~A} 146 \mathrm{~T})$, and 10 (6,3\%) showed BRAF mutation (all V600E). No significant correlations between KRAS and BRAF mutations and various clinicopathological parameters was found.

This is the first report of KRAS and BRAF status in Albanian patients with colorectal carcinoma (CRC) and though the relatively small sample size might not provide enough statistics power.

Conclusions: The results of KRAS and BRAF mutation analysis could be used in the selection of patients for anti-EGFR therapy.

Virtual Slides: The virtual slide(s) for this article can be found here: http://www.diagnosticpathology.diagnomx.eu/vs/ 13000_2014_187

Keywords: Colorectal cancer, KRAS, BRAF, Albania

\section{Background}

Colorectal cancer (CRC) is the third most common malignancy in men and women with an incidence of $1,234,000$ cases contributing $10 \%$ of the total burden [1]. The incidence rates of colon cancer vary in various geographic locations with highest rates estimated in Australia/New Zealand and Western Europe [2].

The development of CRC is a multistep process that occurs because of the accumulation of several genetic alterations, including chromosomal abnormalities, gene mutations, and epigenetic modifications involving several

\footnotetext{
* Correspondence: lorenzo.memeo@grupposamed.com

'IOM Ricerca Srl, Catania, Italy

${ }^{4}$ Department of Experimental Oncology, Mediterranean Institute of

Oncology, Via Penninazzo 7, 95029 Viagrande, Catania, Italy

Full list of author information is available at the end of the article
}

genes that regulate proliferation, differentiation, apoptosis, and angiogenesis $[3,4]$.

Of the various genetic alterations, an important molecular target for metastatic CRC treatment is the epidermal growth factor receptor (EGFR). EGFR, a tyrosine kinase receptor belonging to the ErbB family, has been found to play a significant role in the pathogenesis of CRC by inducing downstream signaling pathways, such as the phosphatidylinositol-3-kinase/Akt and RAS/RAF/ MAP-activated protein kinase (MAPK) pathways.

The EGFR is overespressed in about $50-80 \%$ of CRCs and has been the focus of a new drug development [5] and antibodies targeting EGFR, such as cetuximab and panitumumab, have been examined for therapeutic efficacy in CRC patients [6].

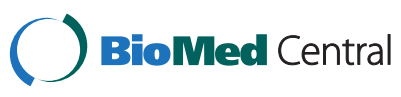


Oncogenic activation of signaling pathways downstream of the EGFR, as induced by mutated KRAS or BRAF, is important for the progression of colorectal cancer [7].

In human CRC, mutations in the KRAS gene have a frequency of around $30 \%-40 \%$ and were linked to poor outcomes, whereas mutations of the BRAF gene, a downstream molecule of KRAS, occur in only $5 \%-10 \%$ of patients with sporadic diseases. Mutations in the $K R A S$ and $B R A F$ genes are frequently found to be mutually exclusive in colorectal cancer $[8,9]$.

Recently, any activating mutations in the $K R A S$ gene has been proved to be predictor of response to epidermal growth factor receptor-targeted therapies, such as cetuximab and panitumumab, for patients with metastatic colorectal cancer [10].

Different somatic missense mutations in codons 12, 13, 61 and 146 are relevant for therapeutic efficacy of anti-EGFR therapy [10-14]. In addition, among colorectal tumors carrying wild-type $K R A S$, mutation of $B R A F$ or NRAS or PIK3CA or loss of PTEN expression may be associated with resistance to EGFR-targeted monoclonal antibody treatment, although these additional biomarkers require further validation before incorporation into clinical practice [15].

Activating mutations of these oncogenes are point mutations (missense mutations) and they arise early during the development of colorectal cancer [16]. The activating mutations in KRAS oncogene are found mostly in codons 12 and 13 (>90\%) but also affect codons 61 and 146 [12,13]. The most frequently observed types of mutations are $\mathrm{G}>\mathrm{A}$ transitions, $\mathrm{G}>\mathrm{T}$ and $\mathrm{G}>\mathrm{C}$ transversions [17]. Identification of somaticactivating mutations of $B R A F$ has been reported in various cancers, with by far the most common mutation being a $1799 \mathrm{~T}>\mathrm{A}$ transversion leading to a Val600Glu (V600E) substitution [9].

Recent studies have demonstrated that a wild type BRAF is also required for response to panitumumab or cetuximab, suggesting that BRAF evaluation should be used together with KRAS for selecting the patients who could benefit from the anti-EGFR therapy $[18,19]$.

In the present study, we detected mutations of KRAS and BRAF proto-oncogenes in tumoral tissue specimens in CRC patients of the Albanian population.

Correlations with various clinicopathological characteristics of patients were further analyzed. To our knowledge, we are the first to report the frequency and type of KRAS and BRAF mutations in Albanian patients with advanced $\mathrm{CRC}$ in order to introduce targeted therapy in the therapeutic modalities for management of this cancer in Albania.

Further researches are needed to determine how the racial differences and etiological factors can influence the spectrum and frequency of KRAS and BRAF mutations between different populations.

\section{Methods}

\section{Patients and specimens}

Tumor specimens used in this study were obtained from 159 CRC consecutive patients who underwent tumor resection at Tirana University Hospital during the period 2012-2013.

The study included 159 patients with histopathologically proven colorectal cancer; two pathologists independently confirmed the diagnosis.

Tumor stage was classified according to the Tumor, Node and Metastases (TNM) classification of the Union for International Cancer Control (UICC) staging.

The present study received the IRB approval from University of Tirana (\#12; 21/02/2014).

\section{Histological examination}

Tumors were classified as well-, moderately or poorly differentiated adenocarcinoma in accordance with the World Health Organization Classification (Jass JR, Sobin LH. Histological typing of intestinal tumors. In World Health Organization, ed. International Histological Classification of Tumors, 2nd edn. Berlin: Springer, 1989; 29-40). Mucinous tumors were separately classified.

Additional histological features such as necrosis, tumor vascular invasion, stromal desmoplastic reaction and infiltrative versus expansive pattern of growth, have been evaluated but not considered as variable parameters for statistical analysis.

\section{DNA isolation}

Sections (5 micron) were cut from paraffin-embedded tumor tissue blocks and stained with haematoxylin \& eosin (H\&E) for histopathological examination.

For DNA isolation, 5 sections, each of 4 micron thickness, were used for each case. The H\&E section was used as a reference and tumor tissue was macrodissected from the normal colonic epithelium and scraped off.

Genomic DNA was extracted from formalin-fixed paraffin-embedded (FFPE) tissue samples using the QIAamp DNA FFPE tissue kit (Qiagen) according to the manufacturer's recommendations and was amplied by PCR at KRAS exon 2, 3 and 4 and BRAF exon 15.

\section{Analysis of KRAS and BRAF mutations}

Mutation analysis of KRAS codons 12, 13, 61, 146 and BRAF codon 600 was carried out by direct sequencing of amplified PCR products.

PCR was performed using $50 \mathrm{ng}$ genomic DNA as template. Each mixture contained 8 pmol of each primer. Primers were purchased from Roche Dagnostics Spa, Monza, Italia.

The reactions were performed in $1 \mathrm{X}$ GeneAmp 10X PCR Buffer II (Applied Biosystems), $0.25 \mu \mathrm{mol} / \mathrm{L}$ dNTPs, 
$2 \mathrm{mmol} / \mathrm{L} \mathrm{MgCl} 2$ solution, and $1.25 \mathrm{U}$ AmpliTaq DNA Polymerase (Applied Biosystems, CA USA).

The amplification reactions were as follows: an initial denaturation cycle of $95^{\circ} \mathrm{C}$ for $5 \mathrm{~min} ; 45$ cycles of denaturation $\left(95^{\circ} \mathrm{C}\right.$ for $\left.30 \mathrm{~s}\right)$, annealing $\left(60^{\circ} \mathrm{C}\right.$ for $30 \mathrm{~s}$ for KRAS exon $2,55^{\circ} \mathrm{C}$ for $30 \mathrm{~s}$ for KRAS exon 3,4 and $57^{\circ} \mathrm{C}$ for $30 \mathrm{~s}$ for BRAF exon 15), and elongation $\left(72^{\circ} \mathrm{C}\right.$ for $1 \mathrm{~min}$ ); and a final extension cycle at $72^{\circ} \mathrm{C}$ for $5 \mathrm{~min}$.

The PCR products were purified with $1 \mathrm{ml}$ ExoI/SAP $\left(37^{\circ} \mathrm{C}\right.$ for 15 minutes, then $85^{\circ} \mathrm{C}$ for 15 minutes) and were then sequenced directly on both strands using the BigDyeH Terminator v1.1 cycle sequencing kit (Applied Biosystems) according to manufacturer's protocol and analysed by the ABI 3500 Genetic Analyzer (Applied Biosystem, CA, USA).

\section{Results}

Of the 159 patients, 90 were male and 69 female; ranged from 17 to 85 years of age (median 61.7). 24 patients were stage I, 36 stage II, 84 stage III and 15 stage IV.

KRAS mutational status was tested in 159 clinical samples of which $28(17,6 \%)$ harboured at least one mutation at codon 12, 13 or 146 .

Specific nucleotide and codon changes detected are listed in Table 1.

Mutations at codon 12 are the more frequent ones, followed by codon 13 and 146 ones. No point mutation was detected in KRAS at codon 61. 25 samples showed a mutation at codon 12, 2 at codon 13 and 1 at codon 146. The incidence of KRAS mutation was similar in men and women. The predominant mutations were $\mathrm{G}>\mathrm{A}$ transition while the most frequent mutation was G12D (8.1\% of all mutations). Representative electropherograms of KRAS wild type and G12D are shown in Figure 1.

Of the 131 KRAS wild type samples, 10 (6,3\%) harboured a mutation at codon 600 in exon 15 of BRAF (V600E) (Table 2).

Table 1 Frequency of Mutations in KRAS codon 12, 13, 61 and $146(\mathrm{~N}=159)$

\begin{tabular}{lll}
\hline Nucleotide change & Aminoacid change & N. of mutated cases (\%) \\
\hline KRAS codon 12 & & $13(8.1)$ \\
c.35G > A & p.G12D & $1(0.6)$ \\
c.34G > A & p.G12S & $4(2.5)$ \\
c.35G > T & p.G12V & $4(2.5)$ \\
c.34G > T & p.G12C & $3(1.9)$ \\
c.35G > C & p.G12A & \\
KRAS codon 13 & & $2(1.3)$ \\
c.38G > A & p.G13D & \\
KRAS codon 61 & & 0 \\
$/$ & $/$ & $1(0.6)$ \\
KRAS codon 146 & & \\
c.436G > A & p.A146T
\end{tabular}

Representative electropherograms of BRAF wild type and with a V600E mutation are shown in Figure 2. In addition, our data confirmed that mutations in KRAS and BRAF are mutually exclusive.

All mutations found had previously been described to be oncogenically active and were found in the COSMIC (catalog of somatic mutations in cancer) database (Sanger Institute, Cambridge, UK).

No association between KRAS and BRAF mutations and various clinicopathological features such as age, gender, tumor differentiation, UICC classification was found (Table 3).

\section{Discussion}

The epidermal growth factor receptor (EGFR) plays a key role in the development and progression of CRC. It triggers a downstream signaling cascade such as RAS-RAFMAPK and PI3K-AKT pathway, which are involved in cell proliferation, differentiation, survival and invasion. Among the activating mutations downstream of EGFR, KRAS and BRAF oncogenes participate in the MAPK pathway that mediates cellular response to growth signals [20]. This cascade is activated by the EGFR [21] that is overespressed in $50-80 \%$ of colorectal tumors and therefore represent a suitable target for the anticancer therapies with monoclonal antibodies as cetuximab and paninutumab [22,23]. These molecules bind to the extracellular domain of EGFR leading to the inhibition of its downstream signaling.

The anti-EGFR therapies have shown to be effective only in a subset of patients with colorectal cancer [24]. To optimize the benefits and to reduce the risks of antiEGFR therapies, the EGFR, as well as the molecules involved in its pathway, has been evaluated as potential marker to predict the treatment outcomes. Recents studies have demonstrated that mutations in the KRAS gene negatively predict the response to EGFR-targeted therapies in patients with metastatic colorectal cancer $[25,26]$. The KRAS mutations that are responsible for the synthesis of a permanently active KRAS protein $[27,28]$ are predominately identified in the 12 and 13 codon of the gene [28]. Despite having a wild type KRAS, only 40$60 \%$ of the patients will respond to treatment [29]. The identification of the other important molecular determinants of response is therefore of an outmost importance.

The BRAF-activating mutations have been reported in various type of cancer: melanoma (70\% of cases), thyroid (30-70\%), ovarian (15-30\%) and colorectal cancer (5$10 \%)[30,31]$. All BRAF mutations occur within the kinase domain resulting in an elevated kinase activity of the BRAF protein. The p. Val600Glu (V600E) mutation is the most common mutation in the BRAF gene, found in approximately $80 \%$ of the cases $[9,19]$. Certain studies have demonstrated that wild type BRAF is required for response to panitumumab or cetuximab, suggesting that 


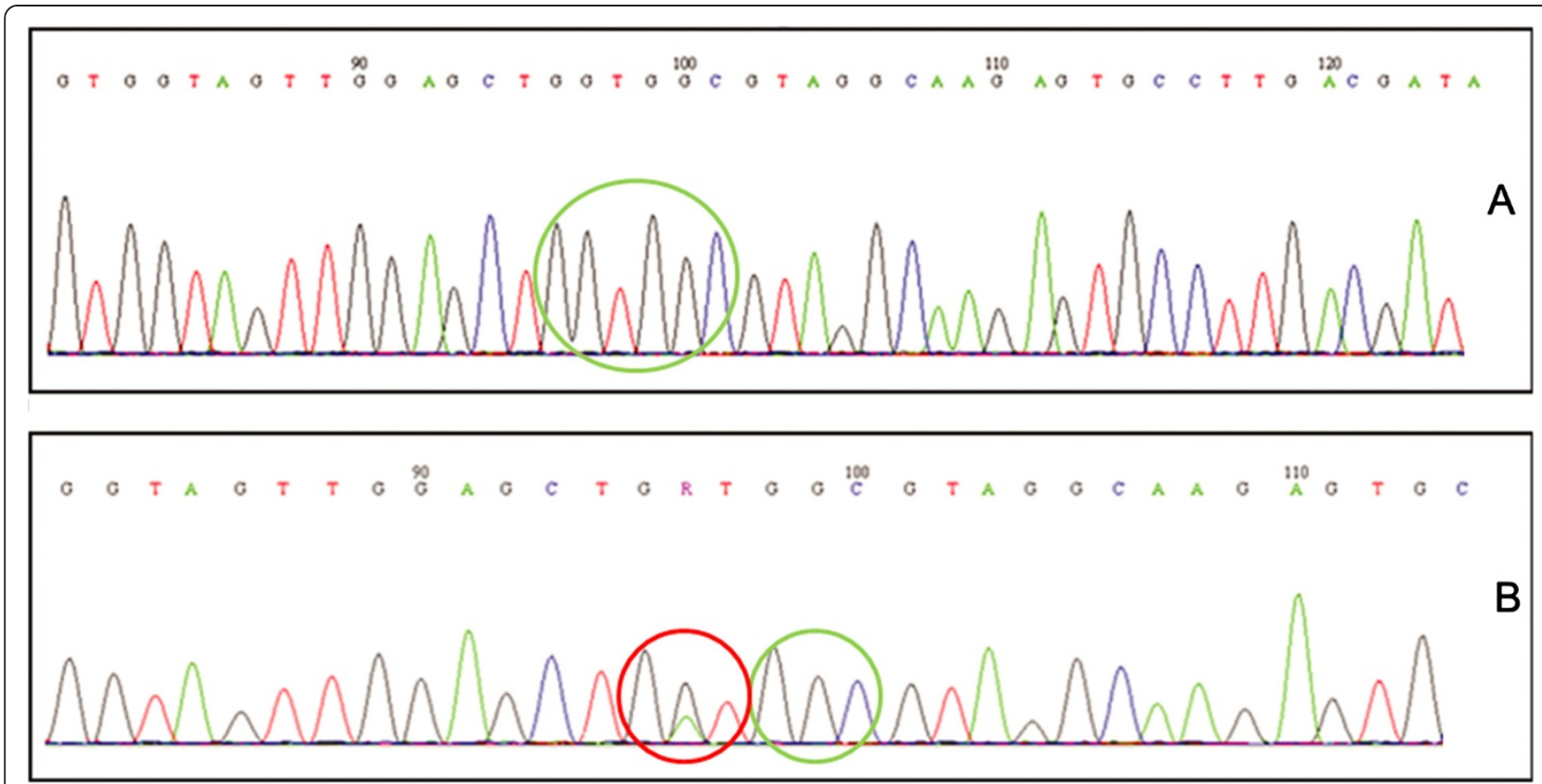

Figure 1 Sequencing electropherogram of KRAS exon 2. (A) Wild-type. (B) G12D mutation.

BRAF should also be tested together with KRAS to select the patients who are most likely to benefit from the antiEGFR therapy $[19,32,33]$. Our objective was the determine the frequency of most common mutations in KRAS gene (p.G12D, p.G12V, p.G12A, p.G12C, p.G12S, p.G12R, p. G13D, p.Q61H, p.Q61L, p.Q61R, p.A146T, p.A146V, p. A146P) together with the BRAF V600E mutation in Albanian patients with metastatic colorectal cancer.

In our study, we have evaluated KRAS and BRAF mutational status in 159 Albanian CRC patients using direct sequencing. The present study is first to provide data on frequency and type of KRAS and BRAF mutations of colorectal cancer in Albanian population; no data is present in the literature about this incidence.

In addition, we also tried correlate the presence of KRAS and BRAF mutations at codon 12, 13, 61, 146 and 600 with various clinicopathological features such as age, gender and grade as shown in Table 3.

In the present study, we did not find any significant correlations between these molecular events and various clinicopathological features, which may be partly attributable to the relatively small sample size.

In summary, our study reports that the incidence of KRAS mutation in Albanian colorectal cancer patients is

Table 2 Frequency of BRAF Mutations in Tumor Wild type for KRAS codon 12, 13, 61 and $146(N=131)$

Nucleotide change Aminoacid change No. of mutated cases (\%) BRAF codon 600

C. $1799>\mathrm{A}$ p. V600E

$10(6.3 \%)$ less frequent when compared with the data from literature (35-50\%) [14,34-37].

This is probably due to the different methodology since we used direct sequencing and to small sample size.

Studies from various countries have analyzed the frequency of the type of KRAS point mutation in CRC. Most of the authors have identified the G > A transition as the most frequently found type of KRAS mutation $[38,39]$. In the current study, the $G>A$ transition appeared also to be the predominant mutation, followed by $\mathrm{G}>\mathrm{T}$ transversion. Among mutations in codons 12, the substitution of glycine with aspartate has been reported as the most frequent change. In accordance with our data, previous studies have usually identified the glycine to aspartate transition on codon 12 (p.G12D) as the most frequent mutation of KRAS [40-48].

The percentage of BRAF mutation is similar to the published data reporting the BRAF V600E mutation in the range of 5 to $10 \%[19,49]$.

Although the mutations in KRAS are considered to be a highly specific negative marker of response to cetuximab and panitumumab, the selection of patients for anti-EGFR treatment on such basis is not sensitive enough. Moreover, it has been reported that patients with activating mutations in RAS, in addition to KRAS exon 2, do not benefit from combined panitumumab plus FOLFOX4 chemiotherapy [10].

Therefore, the BRAF mutational status is of utmost importance to be verified as another molecular determinant of response to anti-EGFR targeted monoclonal antibody therapy. 


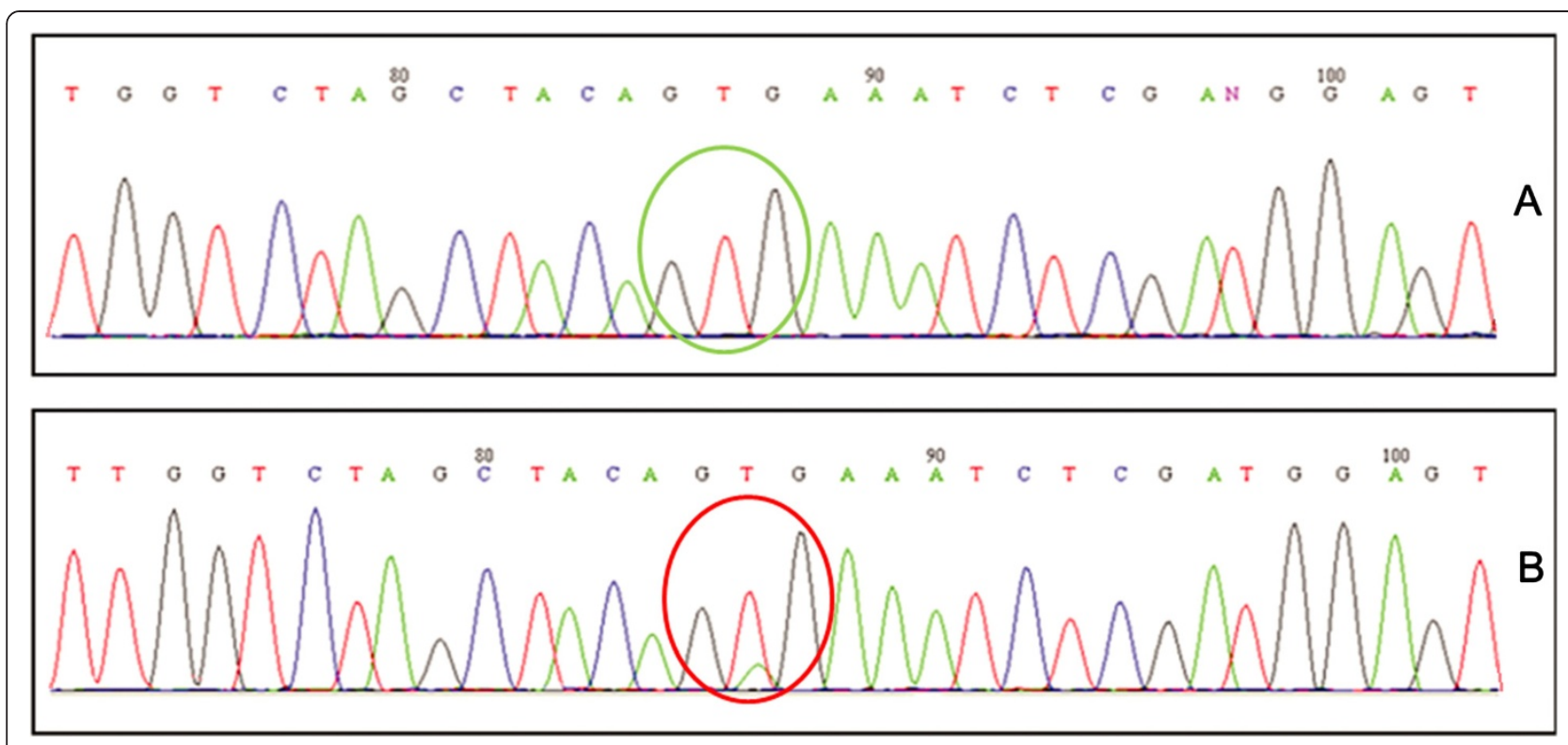

Figure 2 Sequencing electropherogram of BRAF exon 15. (A) Wild-type. (B) V600E mutation.

In our group, we found 10 patients with the V600E mutation in BRAF. These 10 patients represent $6.3 \%$ of all tested patients.

All 10 patients with the V600E mutation in BRAF were wild-type KRAS, and no BRAF mutations were found in patients with a mutated KRAS genotype. This also is in concordance with previously published observations by

Table 3 Correlation between KRAS, BRAF mutations and clinicopathological parameters in colorectal cancer (\%)

\begin{tabular}{|c|c|c|c|c|}
\hline Terms & All & Wild type & KRAS Mutation & BRAF Mutation \\
\hline No.of patients & 159 & 122 & $28(17,6 \%)$ & $10(6,3 \%)$ \\
\hline Median age & 61,7 & & & \\
\hline \multicolumn{5}{|l|}{ Gender } \\
\hline Male & 90 & 69 & $18(20 \%)$ & $3(3,3 \%)$ \\
\hline Female & 69 & 53 & $10(14,5 \%)$ & $7(10,1 \%)$ \\
\hline \multicolumn{5}{|l|}{ Differentiation } \\
\hline Poor & 12 & 11 & / & $1(8,3 \%)$ \\
\hline Moderate & 76 & 57 & $17(22 \%)$ & $3(3,9 \%)$ \\
\hline Mucinose & 16 & 12 & $3(18,7 \%)$ & $1(6,2 \%)$ \\
\hline Well & 52 & 39 & $8(15,3 \%)$ & $5(9,6 \%)$ \\
\hline \multicolumn{5}{|c|}{ UICC classification } \\
\hline । & 24 & 17 & $5(20,8)$ & $2(8,3 \%)$ \\
\hline$\| \mathrm{A}$ & 36 & 26 & $7(19,4)$ & $3(8,3 \%)$ \\
\hline$\| I I A$ & 10 & 9 & $1(10 \%)$ & / \\
\hline$\| I I B$ & 70 & 55 & $11(16 \%)$ & $5(7.1 \%)$ \\
\hline IIIC & 4 & 3 & $1(25 \%)$ & / \\
\hline IV & 15 & 12 & $3(20 \%)$ & / \\
\hline
\end{tabular}

other authors that mutations in KRAS and BRAF are mutually exclusive [8].

\section{Conclusions}

In conclusion, we observed a frequency of $17,6 \%$ for mutations in exon 2, 3 and 4 of the KRAS oncogene, predominantly in codon 12 . The $\mathrm{G}>\mathrm{A}$ transition and $\mathrm{G}>\mathrm{T}$ transversion were the most frequently observed mutations, with the $\mathrm{G}>\mathrm{T}$ transversion confined to codon 12 .

Summing up the results about the KRAS and the BRAF mutation carriers from our study, the portion of potentially non-responsive patients for the anti-EGFR treatment is $23,3 \%$.

Thus, the anti-EGFR therapy could be beneficial for the majority of Albanian population.

The results of this study indicate that the types of KRAS mutations from CRC in Albania are similar to other countries but with a lower frequency.

A limitation of this study is the absence of data on NRAS mutations, considering that patients with RAS mutations (KRAS or NRAS) do not respond to antiEGFR therapy.

These data should be confirmed on a larger study group and in prospective studies in order to determine whether these mutations contribute to progression of CRC.

\section{Consent}

Written informed consent was obtained from the patients for the publication of this study and any accompanying images. 


\section{Abbreviations}

CRC: Colorectal cancer; EGFR: Epidermal growth factor receptor; TNM: Tumor, node and metastases; UICC: Classification of the Union for International Cancer Control staging; H\&E: Haematoxylin \& eosin; FFPE: Formalin-fixed paraffin-embedded.

\section{Competing interests}

The authors declare that they have no competing interests.

\section{Authors' contributions}

DM carried out the molecular studies and drafted the manuscript. RC carried out the molecular studies. SK participated in the design of the study and collected the samples. MA participated in the design of the study and collected the samples. CC participated in the design of the study. VC participated in the design of the study. MB participated in the design of the study. LM conceived the study, participated in its design and drafted the manuscript. All authors read and approved the final manuscript.

\section{Acknowledgments}

We would like to thank Giovanni Ferlito for his expert technical support.

\section{Author details}

${ }^{1}$ IOM Ricerca Srl, Catania, Italy. ${ }^{2}$ Morphopathology Laboratories, Tirana, Albania. ${ }^{3}$ Department of Pathology, University of Tirana, Tirana, Albania. ${ }^{4}$ Department of Experimental Oncology, Mediterranean Institute of Oncology, Via Penninazzo 7, 95029 Viagrande, Catania, Italy. ${ }^{5}$ Division of Pathology, Centro di Riferimento Oncologico, Aviano, Italy. ${ }^{6}$ Department of Clinical Oncology, Centro di Riferimento Oncologico, Aviano, Italy.

Received: 6 August 2014 Accepted: 7 September 2014

Published online: 30 September 2014

\section{References}

1. Ferlay J, Shin HR, Bray F, Forman D, Mathers C, Parkin DM: Estimates of worldwide burden of cancer in 2008: GLOBOCAN 2008. Int J Cancer 2010, 127:2893-2917.

2. Jemal A, Siegel R, Ward E, Murray T, Xu J, Thun MJ: Cancer statistics, 2007. CA Cancer J Clin 2007, 57:43-66.

3. Russo A, Rizzo S, Bronte G, Silvestris N, Colucci G, Gebbia N, Bazan V, Fulfaro F: The long and winding road to useful predictive factors for anti-EGFR therapy in metastatic colorectal carcinoma: the KRAS/BRAF pathway. Oncology 2009, 77(Suppl 1):57-68.

4. Vogelstein B, Fearon ER, Hamilton SR, Kem SE, Preisinger AC, Leppert M, Nakamura Y, White R, Smits AM, Bos JL: Genetic alterations during colorectal tumor development. Engl J Med 1998, 319(9):525-532.

5. Porebska I, Harlozińska A, Bojarowski T: Expression of the tyrosine kinase activity growth factor receptors (EGFR, ERB B2, ERB B3) in colorectal adenocarcinomas and adenomas. Tumour Biol 2000, 21(2):105-115.

6. Reynolds NA, Wagstaff AJ: Cetuximab: in the treatment of metastatic colorectal cancer. Drugs 2004, 64(1):109-118.

7. Benvenuti S, Sartore-Bianchi A, Di Nicolantonio F, Zanon C, Moroni M, Veronese $S$, Siena S, Bardelli A: Oncogenic activation of the RAS/RAF signaling pathway impairs theresponse of metastatic colorectal cancers to anti-epidermal growth factor receptor antibody therapies. Cancer Res 2007, 67(6):2643-2648.

8. Rajagopalan H, Bardelli A, Lengauer C, Kinzler KW, Vogelstein B, Velculescu VE: Tumorigenesis: RAF/RAS oncogenes and mismatch-repair status. Nature 2002, 418(6901):934.

9. Davies H, Bignell GR, Cox C, Stephens P, Edkins S, Clegg S, Teague J, Woffendin H, Garnett MJ, Bottomley W, Davis N, Dicks E, Ewing R, Floyd Y, Gray K, Hall S, Hawes R, Hughes J, Kosmidou V, Menzies A, Mould C, Parker A, Stevens C, Watt S, Hooper S, Wilson R, Jayatilake H, Gusterson BA, Cooper C, Shipley J, et al: Mutations of the BRAF gene in human cancer. Nature 2002, 417(6892):949-954.

10. Douillard JY, Oliner KS, Siena S, Tabernero J, Burkes R, Barugel M, Humblet Y, Bodoky G, Cunningham D, Jassem J, Rivera F, Kocákova I, Ruff P, BłasińskaMorawiec M, Šmakal M, Canon JL, Rother M, Williams R, Rong A, Wiezorek J, Sidhu R, Patterson SD: Panitumumab-FOLFOX4 treatment and RAS mutations in colorectal cancer. N Engl J Med 2013, 369(11):1023-1034.
11. Russo A, Bazan V, Agnese V, Rodolico V, Gebbia N: Prognostic and predictive factors in colorectal cancer: Kirsten Ras in CRC (RASCAL) and TP53CRC collaborative studies. Ann Oncol 2005, 16(Suppl 4):iv44-iv49.

12. Edkins S, O'Meara S, Parker A, Stevens C, Reis M, Jones S, Greenman C, Davies H, Dalgliesh G, Forbes S, Hunter C, Smith R, Stephens P, Goldstraw P, Nicholson A, Chan TL, Velculescu VE, Yuen ST, Leung SY, Stratton MR, Futreal PA: Recurrent KRAS codon 146 mutations in human colorectalcancer. Cancer Biol Ther 2006, 5(8):928-932.

13. Oliveira C, Westra JL, Arango D, Ollikainen M, Domingo E, Ferreira A, Velho S, Niessen R, Lagerstedt K, Alhopuro P, Laiho P, Veiga I, Teixeira MR, Ligtenberg M, Kleibeuker JH, Sijmons RH, Plukker JT, Imai K, Lage P, Hamelin R, Albuquerque C, Schwartz S Jr, Lindblom A, Peltomaki P, Yamamoto $\mathrm{H}$, Aaltonen LA, Seruca R, Hofstra RM: Distinct patterns of KRAS mutations incolorectal carcinomas according to germline mismatch repair defects and hMLH1 methylation status. Hum Mol Genet 2004, 13(19):2303-2311.

14. Imamura $Y$, Lochhead $P$, Yamauchi M, Kuchiba A, Qian ZR, Liao X, Nishihara R, Jung S, Wu K, Nosho K, Wang YE, Peng S, Bass AJ, Haigis KM, Meyerhardt JA, Chan AT, Fuchs CS, Ogino S: Analyses of clinicopathological, molecular, and prognostic associations of KRAS codon 61 and codon 146 mutations in colorectal cancer: cohort study and literature review. Mol Cancer 2014, 13:135.

15. Siena S, Sartore-Bianchi A, Di Nicolantonio F, Balfour J, Bardelli A: Biomarkers predicting clinical outcome of epidermal growth factor receptor-targeted therapy in metastatic colorectal cancer. J Nat/ Cancer Inst 2009, 101(19):1308-1324.

16. Jones S, Chen WD, Parmigiani G, Diehl F, Beerenwinkel N, Antal T, Traulsen A, Nowak MA, Siegel C, Velculescu VE, Kinzler KW, Vogelstein B, Willis J, Markowitz SD: Comparative lesion sequencing provides insights into tumor evolution. Proc Natl Acad Sci U S A 2008, 105(11):4283-4288.

17. Risio M, Malacarne $D$, Giaretti W: KRAS transitions and villous growth in colorectal adenomas. Cell Oncol 2005, 27(5-6):363-366.

18. Karapetis CS, Khambata-Ford S, Jonker DJ, O'Callaghan CJ, Tu D, Tebbutt NC, Simes RJ, Chalchal H, Shapiro JD, Robitaille S, Price TJ, Shepherd L, Au HJ, Langer C, Moore MJ, Zalcberg JR: K-ras mutations and benefit from cetuximab in advanced colorectal cancer. N Engl J Med 2008, 359(17):1757-1765.

19. Di Nicolantonio F1, Martini M, Molinari F, Sartore-Bianchi A, Arena S, Saletti P, De Dosso S, Mazzucchelli L, Frattini M, Siena S, Bardelli A: Wild Type BRAF is required for response to panitumumab or cetuximab in metastatic colorectal cancer. J Clin Oncol 2008, 26(35):5705-5712.

20. Peyssonnaux C, Eychene A: The Raf/MEK//ERK pathway: new concepts of activation. Biol Cell 2001, 93(1-2):53-62

21. Harari PM, Allen GW, Bonner JA: Biology of interactions: anti-epidermal growth factor receptor agents. J Clin Oncol 2007, 25(26):4057-4065.

22. Hemming AW, Davis NL, Kluftinger A, Robinson B, Quenville NF, Liseman B, LeRiche J: Prognostic markers of colorectal cancer: an evaluation of DNA content, epidermal growth factor receptor, and ki-67. J Surg Oncol 1992, 51(3):147-152

23. Bonomi PD, Buckingham $L$, Coon J: Selecting patients for treatment with epidermal growth factor tyrosine kinase inhibitors. Clin Cancer Res 2007, 13(15Pt2):s4606-s4612

24. Dassonville O, Bozec A, Fischel JL, Milano G: EGFR targeting therapies: monoclonal antibodies versus tyrosine kinase inhibitors. Similarities and differences. Crit Rev Oncol Hematol 2007, 62(1):53-61.

25. Amado RG, Wolf M, Peeters M, Van Cutsem E, Siena S, Freeman DJ, Juan T, Sikorski R, Suggs S, Radinsky R, Patterson SD, Chang DD: Wild-type KRAS is required for panitumumab efficacy in patients with metastatic colorectal cancer. J Clin Oncol 2008, 26(10):1626-1634

26. De Roock W, Piessevaux H, De Schutter J, Janssens M, De Hertogh G, Personeni N, Biesmans B, Van Laethem JL, Peeters M, Humblet $Y$, Van Cutsem E, Tejpar S: KRAS wild-type state predicts survival and is associated to early radiological response in metastatic colorectal cancer treated with cetuximab. Ann Oncol 2008, 19(3):508-515.

27. Zenker M, Lehmann K, Schulz AL: Expansion of the genotypic and phenotypic spectrum in patients with KRAS germline mutations. J Med Genet 2007, 44(2):131-135.

28. Van Krieken $\mathrm{JH}$, Jung A, Kirchner T, Carneiro F, Seruca R, Bosman FT, Quirke P, Fléjou JF, Plato Hansen T, de Hertogh G, Jares P, Langner C, Hoefler G, Ligtenberg M, Tiniakos D, Tejpar S, Bevilacqua G, Ensari A: KRAS mutation testing for predicting response to anti-EGFR therapy for colorectal carcinoma proposal for an European quality assurance program. Virchows Arch 2008, 453(5):417-431. 
29. Linardou H1, Dahabreh IJ, Kanaloupiti D, Siannis F, Bafaloukos D, Kosmidis P, Papadimitriou CA, Murray S: Assessment of somatic k-RAS mutations as a mechanism associated with resistance to EGFR-targeted agents: a systematic review and meta-analysis of studies in advanced non-small-cell lung cancer and metastatic colorectal cancer. Lancet Oncol 2008, 9(10):962-972.

30. Sala E, Mologni L, Truffa S, Gaetano C, Bollag GE, Gambacorti-Passerini C: BRAF silencing by short hairpin RNA or chemical blockade by PLX4032 leads to different responses in melanoma and thyroid carcinoma cells. Mol Cancer Res 2008, 6(5):751-759.

31. Kumar R, Angelini S, Czene K, Sauroja I, Hahka-Kemppinen M, Pyrhönen S, Hemminki K: BRAF mutations in metastatic melanoma: a possible association with clinical outcome. Clin Cancer Res 2003, 9(9):3362-3368.

32. Loupakis F, Ruzzo A, Cremolini C, Vincenzi B, Salvatore L, Santini D, Masi G, Stasi I, Canestrari E, Rulli E, Floriani I, Bencardino K, Galluccio N, Catalano V, Tonini G, Magnani M, Fontanini G, Basolo F, Falcone A, Graziano F: KRAS codon 61, 146 and BRAF mutations predict resistance to cetuximab plus irinotecan in KRAS codon 12 and 13 wild-type metastatic colorectal cancer. Br J Cancer 2009, 101(4):715-721.

33. Laurent-Puig P, Cayre A, Manceau G: Analysis of PTEN, BRAF, and EGFR status in determining benefit from cetuximab therapy in wild-type KRAS metastatic colon cancer. J Clin Oncol 2009, 27(35):5924-5930.

34. Ozen F, Ozdemir S, Zemheri E, Hacimuto G, Silan F, Ozdemir O: The protoncogene KRAS and BRAF profiles and some clinical charateristics in colonrectal cancer in the Turkish population. Genet Test Mol Biomarkers 2013, 17(2):135-139.

35. Rako I, J. Jakic-Razumovic J, Katalinic D, Sertic J, Plestina S: Mutation pattern of KRAS and BRAF oncogenes in colorectal cancer patients. Neoplasma 2012, 59(4):376-383.

36. Bozzao C, Varvara D, Piglionica M, Bagnulo R, Forte G, Patruno M, Russo S, Piscitelli D, Stella A, Resta N: Survey of KRAS, BRAF and PIK3CA mutational status in 209 consecutive Italian colorectal cancer patients. Int J Biol Markers 2012, 27(4):e366-e374.

37. Vaughn CP, Zobell SD, Furtado LV, Baker CL, Samowitz WS: Frequency of KRAS, BRAF, and NRAS mutations in colorectal cancer. Genes Chromosomes Cancer 2011, 50(5):307-312.

38. Topal MD: DNA repair, oncogenes and carcinogenesis. Carcinogenesis 1998, 9(5):691-696.

39. Zarbl H, Sukumar S, Arthur AV, Martin-Zanca D, Barbacid M: Direct mutagenesis of Ha-ras-1 oncogenes by N-nitroso-N- methylurea during initiation of mammary carcinogenesis in rats. Nature 1985 315(6018):382-385.

40. Adams R, Meade A, Wasan H, Griffiths G, Maughan T: Cetuximab therapy in first-line metastatic colorectal cancer and intermittent palliative chemotherapy: review of the COIN trial. Expert Rev Anticancer Ther 2008, 8:1237-1245.

41. Andreyev HJ, Norman AR, Cunningham D, Oates JR, Clarke PA: Kirsten ras mutations in patients with colorectal cancer: the multicenter "RASCAL" study. J Natl Cancer Inst 1998, 90(9):675-684

42. Barault L1, Veyrie N, Jooste V, Lecorre D, Chapusot C, Ferraz JM, Lièvre A, Cortet M, Bouvier AM, Rat P, Roignot P, Faivre J, Laurent-Puig P, Piard F: Mutations in the RAS-MAPK, PI(3)K (phosphatidylinositol-3-OH kinase) signaling network correlate with poor survival in a population-based series of colon cancers. Int J Cancer 2008, 122(10):2255-2259.

43. Cerottini JP, Caplin S, Saraga E, Givel JC, Benhattar J: The type of K-ras mutation determines prognosis in colorectal cancer. Am J Surg 1998, 175(3):198-202.

44. Di Fiore F, Blanchard F, Charbonnier F, Le Pessot F, Lamy A, Galais MP, Bastit L, Killian A, Sesboüé R, Tuech JJ, Queuniet AM, Paillot B, Sabourin JC, Michot $F$, Michel P, Frebourg T: Clinical relevance of KRAS mutation detection in metastatic colorectal cancer treated by Cetuximab plus chemotherapy. Br J Cancer 2007, 96(8):1166-1169.

45. Kressner U1, Bjørheim J, Westring S, Wahlberg SS, Påhlman L, Glimelius B, Lindmark G, Lindblom A, Børresen-Dale AL: Ki-ras mutations and prognosis in colorectal cancer. Eur J Cancer 1998, 34(4):518-521.

46. Moerkerk P, Arends JW, Van Driel M, De Bruine A, De Goeij A, Ten Kate J: Type and number of Ki-ras point mutations relate to stage of human colorectal cancer. Cancer Res 1994, 54(13):3376-3378.

47. Span M, Moerkerk PT, De Goeij AF, Arends JW: A detailed analysis of K-ras point mutations in relation to tumor progression and survival in colorectal cancer patients. Int J Cancer 1996, 69(3):241-245.
48. Urosevic N, Krtolica K, Skaro-Milic A, Knezevic-Usaj S, Dujic A: Prevalence of G-to-T transversions among K-ras oncogene mutations in human colorectal tumors in Yugoslavia. Int J Cancer 1993, 54(2):249-254.

49. Yuen ST, Davies H, Chan TL, Ho JW, Bignell GR, Cox C, Stephens P, Edkins S, Tsui WW, Chan AS, Futreal PA, Stratton MR, Wooster R, Leung SY: Similarity of the phenotypic patterns associated with BRAF and KRAS mutations in colorectal neoplasia. Cancer Res 2002, 62(22):6451-6455.

doi:10.1186/s13000-014-0187-7

Cite this article as: Martinetti et al:: KRAS and BRAF mutational status in colon cancer from Albanian patients. Diagnostic Pathology 2014 9:187.

\section{Submit your next manuscript to BioMed Central and take full advantage of:}

- Convenient online submission

- Thorough peer review

- No space constraints or color figure charges

- Immediate publication on acceptance

- Inclusion in PubMed, CAS, Scopus and Google Scholar

- Research which is freely available for redistribution 